\title{
Ebselen suppresses inflammation induced by Helicobacter pylori lipopolysaccharide via the p38 mitogen-activated protein kinase signaling pathway
}

\author{
LING XU ${ }^{1 *}$, CHANGGUO GONG ${ }^{1 *}$, GUANGMING LI $^{2}$, JUE WEI ${ }^{1}$, TING WANG ${ }^{1}$, \\ WENYING MENG ${ }^{1}$, MIN SHI ${ }^{1}$ and YUGANG WANG ${ }^{1}$ \\ ${ }^{1}$ Department of Gastroenterology, Shanghai Tongren Hospital Affiliated to Shanghai Jiao Tong University \\ School of Medicine, Shanghai 200336; ${ }^{2}$ Department of Gastroenterology, Xinhua Hospital, \\ Affiliated to Shanghai Jiao Tong University School of Medicine, Shanghai 200092, P.R. China
}

Received March 11, 2016; Accepted February 23, 2017

DOI: $10.3892 / \mathrm{mmr} .2018 .8641$

\begin{abstract}
Ebselen is a seleno-organic compound that has been demonstrated to have antioxidant and anti-inflammatory properties. A previous study determined that ebselen inhibits airway inflammation induced by inhalational lipopolysaccharide (LPS), however, the underlying molecular mechanism remains to be elucidated. The present study investigated the effect of ebselen on the glutathione peroxidase (GPX)-reactive oxygen species (ROS) pathway and interleukin-8 (IL-8) expression induced by Helicobacter pylori LPS in gastric cancer (GC) cells. Cells were treated with $200 \mathrm{ng} / \mathrm{ml} \mathrm{H}$. pylori-LPS in the presence or absence of ebselen for various durations and concentrations $(\mu \mathrm{mol} / \mathrm{l})$. The expression of toll-like receptor 4 (TLR4), GPX2, GPX4, p38 mitogen-activated protein kinase (p38 MAPK), phosphorylated-p38 MAPK, ROS production and IL-8 expression were detected with western blotting or ELISA. The present study revealed that TLR4 expression was upregulated; however, GPX2 and GPX4 expression was reduced following treatment with $H$. pylori LPS, which led to increased ROS production, subsequently altering the IL-8 expression level in GC cells. Additionally, it was determined that ebselen prevented the reduction in GPX2/4 levels induced by $H$. pylori LPS, however, TLR4 expression was not affected. Ebselen may also block the expression of IL- 8 by inhibiting phosphorylation of p38 MAPK. These data suggest ebselen may inhibit ROS production triggered by $H$. pylori LPS treatment via GPX2/4 instead of TLR4 signaling and reduce
\end{abstract}

Correspondence to: Professor Yugang Wang or Professor Min Shi, Department of Gastroenterology, Shanghai Tongren Hospital Affiliated to Shanghai Jiao Tong University School of Medicine, 1111 Xianxia Street, Shanghai 200336, P.R. China

E-mail: wang_yugang@sina.com

E-mail: shimingdyx@yeah.net

*Contributed equally

Key words: ebselen, Helicobacter pylori, lipopolysaccharide, interleukin-8 phosphorylation of p38 MAPK, resulting in altered production of IL-8. Ebselen may, therefore, be a potential therapeutic agent to mediate $H$. pylori LPS-induced cell damage.

\section{Introduction}

A previous epidemiological study determined that Helicobacter pylori infection may be associated with chronic gastritis (CG), peptic ulcers (PU) and other gastric diseases (1). The International Agency for Research on Cancer officially recognized $H$. pylori as an oncogenic factor in patients with human gastric cancer (GC) (2). H. pylori is a microaerophilic Gram-negative bacterium, and $H$. pylori lipopolysaccharides (LPS) are responsible for the toxicity and contribute to the pathogenesis of CG, PU and GC. However, H. pylori LPS has several unique characteristics, including fewer fatty acid residues and absence of 4-phosphate groups; therefore, it has a distinctive activity by induction of cytokines $(3,4)$. Exposure to $H$. pylori LPS leads to a marked increase in NO and proinflammatory cytokine levels, including interleukin (IL)-8 and toll-like receptor (TLR4) in gastric mucosa $(5,6)$.

Ebselen [2-phenyl-1, 2-benzisoselenazol-3 (2H)-one] is a seleno-organic compound that has an activity similar to glutathione peroxidase (GPX). A previous study identified that ebselen may have antioxidant and anti-inflammatory activity (7), while another determined that ebselen may inhibit airway inflammation induced by inhalational LPS (8). However, the underlying molecular mechanism of its action remains to be elucidated.

The aim of the present study was to investigate the effect of ebselen on inflammation mediated by $H$. pylori LPS in vitro and to determine the underlying molecular mechanisms. The effect of ebselen on proliferation and migration of GC cells was investigated in vitro. The findings of the present study may aid in the identification of the possible association between ebselen and $H$. pylori LPS-induced inflammation in GC cells.

\section{Materials and methods}

Cell culture. Human GC cell lines AGS and MGC-803 were obtained from the Shanghai Institute of Biochemistry and Cell 
Biology, Chinese Academy of Sciences (Shanghai, China). Cells at a density of $1 \times 10^{6} / \mathrm{ml}$ were cultured in $25 \mathrm{~cm}^{2}$ cell culture flasks at $37^{\circ} \mathrm{C}$ in a humidified atmosphere of $5 \% \mathrm{CO}_{2}$ with RPMI-1640 (Thermo Fisher Scientific, Inc., Waltham, MA, USA) supplemented with $10 \%$ fetal calf serum (FCS; Gibco; Thermo Fisher Scientific, Inc.) with $50 \mathrm{U} / \mathrm{ml}$ penicillin and $50 \mu \mathrm{g} / \mathrm{ml}$ streptomycin.

Extraction of LPS. LPS was extracted using hot phenol-water extraction, as previously described (9). A suspension of $500 \mathrm{mg}$ biomass in $50 \mathrm{ml}$ distilled water was mixed with $50 \mathrm{ml} 90 \%$ phenol and mixed at $68^{\circ} \mathrm{C}$ for $20 \mathrm{~min}$. The mixture was subsequently cooled to $4^{\circ} \mathrm{C}$ and centrifuged at $2,800 \times \mathrm{g} 4^{\circ} \mathrm{C}$ for $1 \mathrm{~h}$, the resulting supernatant was separated. Subsequently, the phenol layer was extracted with $50 \mathrm{ml}$ distilled water. Pooled supernatants in the aqueous phase were purified by dialysis using cellulose membranes for $24 \mathrm{~h}$, following centrifugation at $2,800 \mathrm{x} \mathrm{g}, 4$ times for $30 \mathrm{~min}$ the aqueous phase was separated. Crude LPS was resuspended in phosphate buffer containing $10 \mu \mathrm{g} / \mathrm{ml}$ deoxyribonuclease and $100 \mu \mathrm{g} / \mathrm{ml}$ ribonuclease. The solution was incubated for $16 \mathrm{~h}$ at $37^{\circ} \mathrm{C}$ and $750 \mathrm{ml} 90 \%$ phenol in distilled water was added. Following dialysis for $10 \mathrm{~min}$, the solution was centrifuged at $4,500 \mathrm{xg}$ at $4^{\circ} \mathrm{C}$ for $30 \mathrm{~min}$ and the aqueous phase was separated and maintained at $-20^{\circ} \mathrm{C}$.

Analysis of cell viability. Cell viability was quantified using the Cell Counting Kit (CCK)-8 (Dojindo Molecular Technologies, Inc., Kumamoto, Japan), which determined the number of viable cells based on the reduction of water-soluble formazan by the dehydrogenases present in viable cells. Cells were seeded at a density of $2 \times 10^{4} /$ well in 96 -well plates, with $100 \mu \mathrm{l}$ medium/well and were incubated with $0,5,10,15,20,25,50$, 75, and $100 \mu \mathrm{mol} / 1$ ebselen (Sigma-Aldrich, Merck Millipore, Darmstadt, Germany) for $24 \mathrm{~h}$. Three wells of each group were used in repeat experiments. After $24 \mathrm{~h}$ post-attachment, $10 \mu \mathrm{l}$ WST-8 [2-(2-methoxy-4-nitrophenyl)-3-(4-nitrophenyl)-5(2,4-disulfophenyl)-2H-tetrazolium] solution was added to each well and cells were incubated at $37^{\circ} \mathrm{C}$ for $1 \mathrm{~h}$. Absorbance was read at $450 \mathrm{~nm}$ on a microplate reader (SpectraFluor; Tecan, Inc., Zürich, Switzerland).

Western blotting. Cells were seeded at a density of $2 \times 10^{6} /$ well in $90-\mathrm{mm}$ dishes, and 0 or $200 \mathrm{ng} / \mathrm{ml}$ LPS was added. The cells were subsequently incubated with or without $20 \mu \mathrm{mol} / 1$ ebselen for 10, 20, 30, 40, 50 min, 1, 2, 5 or $10 \mathrm{~h}$. Total proteins were extracted by RIPA cell lysis buffer containing $1 \mathrm{mmol} / 1$ PMSF (Beyotime Institute of Biotechnology, Shanghai, China) with a centrifugation at $12,000 \mathrm{x} \mathrm{g}$ for $10 \mathrm{~min}$ at $4^{\circ} \mathrm{C}$. The protein concentrations were determined using a $\mathrm{BCA}$ kit (Beyotime Institute of Biotechnology). A total of $50 \mathrm{mg}$ protein per lane was electrophoresed on a $10 \%$ sodium dodecyl sulfate-polyacrylamide electrophoresis gel and transferred onto a nitrocellulose (NC) membrane. Following three washes with TBST (10 min each), the membrane was blocked by $5 \%$ non-fat milk for $1 \mathrm{~h}$ at room temperature. Then the membranes were incubated with the primary antibody [GPX2, cat. no. ab137431; 1:1,000; GPX4, cat. no. ab125066, 1:1,000; and TLR4, cat. no. ab22048, 1:1,000; all from Abcam, Cambridge, MA, USA; 338 mitogen-activated protein kinase (p38 MAPK), cat. no. 9212, 1:1,000; and phosphorylated (p)-p38 MAPK, cat. no. 4511, 1:1,000; both from Cell Signaling Technology, Inc., Danvers, MA, USA] at $4^{\circ} \mathrm{C}$ overnight. The membraned were washed with TBST for 3 times, 10 min each, incubated with secondary antibody [goat anti-rabbit IgG-peroxidase antibody; cat. no. A0545; Sigma-Aldrich; Merck KGaA, Darmstadt, Germany; goat anti-mouse IgG ( $\mathrm{Fc}$ specific)-peroxidase antibody; cat. no. A0168; Sigma-Aldrich; Merck KGaA] with 1:5,000 dilution at room temperature for $1 \mathrm{~h}$. The membranes were subsequently washed with TBST for 3 times, 10 min each, the membrane was washed three times with TBST and detected with enhanced chemiluminescence (Beyotime Institute of Biotechnology, Haimen, China).

ELISA. Cells were seeded at a density of $2 \times 10^{4} /$ well in 96 -well plates and cultured overnight, followed by serum starvation for $24 \mathrm{~h}$ prior to every experiment. Cells were incubated with 200 or $200 \mathrm{ng} / \mathrm{ml}$ LPS and $20 \mu \mathrm{mol} / 1$ ebselen for $1-5 \mathrm{~h}$. The supernatants obtained by centrifugation at $2,000 \times \mathrm{g}, 4^{\circ} \mathrm{C}$ for 20 min were quantified using the human IL-8 ELISA kit according to the manufacturer's protocol (R\&D Systems, Inc., Minneapolis, MN, USA).

Quantification of reactive oxygen species (ROS) generation. Intracellular ROS accumulation was detected using fluorescence microscopy. Cells were plated at a density of $2 \times 10^{4} /$ well in a 96-well plate and cultured in RPMI-1640 medium supplemented with $10 \%$ FCS. The culture medium was renewed when the cells reached $80 \%$ confluence. Cells were treated with 200 or $200 \mathrm{ng} / \mathrm{ml} \mathrm{LPS}$ and $20 \mu \mathrm{mol} / 1$ ebselen at $37^{\circ} \mathrm{C}$ for 1-4 $\mathrm{h}$. The supernatants were quantified using the Cellular ROS Detection Assay kit (Thermo Fisher Scientific, Inc.).

Statistical analysis. Data are expressed as mean \pm standard deviation. CCK-8 data was analyzed using two-way analysis of variance (ANOVA) followed by the Dunnett's test. Western blot analysis, ROS levels and IL-8 assays, were analyzed using one-way ANOVA followed by a Newman-Keuls post hoc test. $\mathrm{P}<0.05$ was considered to indicate a statistically significant difference.

\section{Results}

Ebselen modulates the viability of $G C$ cells. In order to determine the effect of ebselen on GC cell viability, AGS and MGC-803 cells were treated with various concentrations of ebselen for $24 \mathrm{~h}$, before the cell viability rate was detected by CCK- 8 assay. The assay revealed that different concentrations of ebselen produced different effects on GC cell viability $(\mathrm{F}=18.204 ; \mathrm{P}<0.001$; Fig. 1). Ebselen promoted cell viability at low concentrations, whereas at high concentrations it significantly inhibited cell growth. The effect on cell viability was dose-dependent, with a minimal effect at $20 \mu \mathrm{mol} / 1$; therefore, this concentration was selected for subsequent experiments.

Ebselen inhibits IL-8 production induced by H. pylori LPS. Production of IL-8 in AGS cells treated with 0 and $200 \mathrm{ng} / \mathrm{ml}$ H. pylori LPS for $0-4 \mathrm{~h}$ was detected in the absence or presence of $20 \mu \mathrm{mol} / 1$ ebselen (Fig. 2). Ebselen treatment did not result in any significant differences in IL- 8 release at any time point compared with the $0 \mathrm{~h}$ control (Fig. 2). Stimulation with 


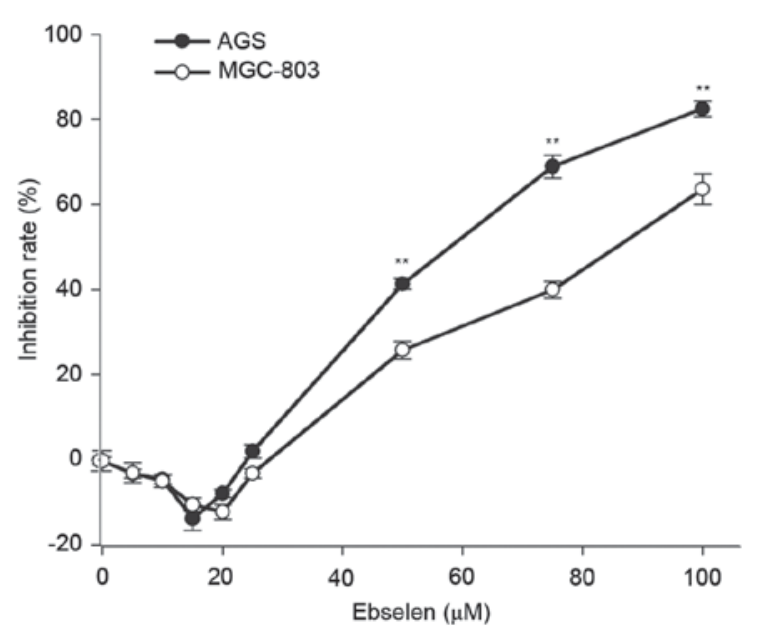

Figure 1. Cell viability changes in gastric cancer cells treated with different concentrations of ebselen. ${ }^{* *} \mathrm{P}<0.01$ vs. $0 \mu \mathrm{M}$.

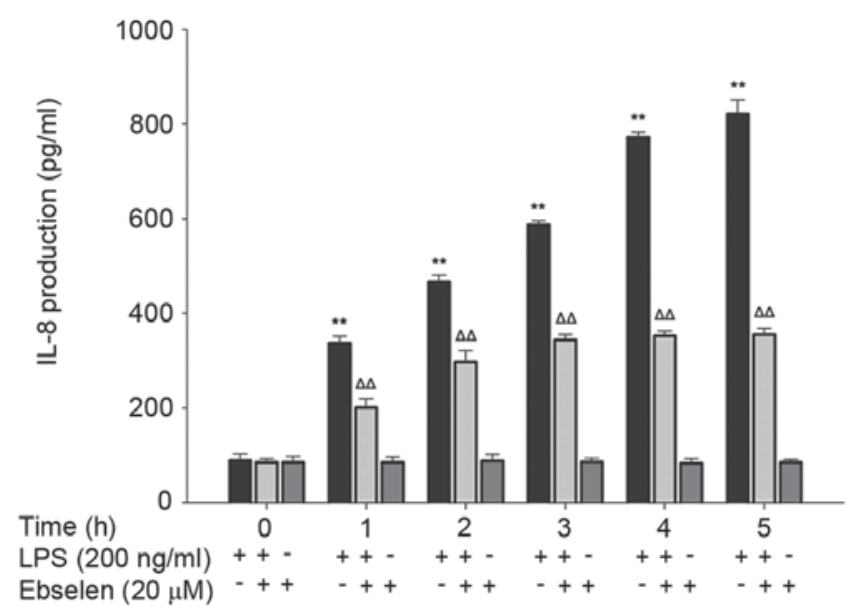

Figure 2. Ebselen blocks IL-8 production induced by Helicobacter pylori LPS in AGS cells. ${ }^{* *} \mathrm{P}<0.01$ vs. LPS treatment alone at $0 \mathrm{~h} ;{ }^{\Delta \Delta} \mathrm{P}<0.01$ vs. LPS+ebselen treatment at $0 \mathrm{~h}$. IL-8, interleukin-8; LPS, lipopolysaccharide.

H. pylori LPS significantly increased IL-8 production in a time-dependent manner $(\mathrm{P}<0.01$; Fig. 2); however, this effect was suppressed by ebselen treatment (Fig. 2). The $1 \mathrm{~h}$ treatment with $200 \mathrm{ng} / \mathrm{ml} \mathrm{H}$. pylori LPS enhanced the production of IL-8 in AGS cells in a time-dependent manner. Simultaneous addition of $20 \mu \mathrm{mol} / 1$ ebselen inhibited the production of IL- 8 in HP-LPS promoted cells. However, in a certain period of time $(3 \mathrm{~h})$, this effect achieved leveled off.

Ebselen inhibits ROS enhanced by H. pylori LPS via activation of GPX signaling. The underlying mechanism that affects IL-8 production was then investigated. ROS are essential components of the innate immune response against intracellular bacteria, and are closely associated with IL-8. Therefore, the effect of ebselen on $H$. pylori LPS-induced ROS was investigated. The levels of ROS generation in ebselen-treated, LPS-treated, and LPS+ebselen-treated AGS cells was measured (Fig. 3A). LPS-treated cells produced more ROS at each time point from $1 \mathrm{~h}$ than ebselen-treated and LPS+ebselen-treated cells (Fig. 3A; LPS vs. ebselen, $\mathrm{P}=0.001$ at $1 \mathrm{~h}, \mathrm{P}<0.001$ at 2, 3 and 4 h; LPS vs. LPS+ebselen, $\mathrm{P}=0.006$ at $1 \mathrm{~h}, \mathrm{P}=0.002$ at $2 \mathrm{~h}, \mathrm{P}<0.001$ at 3 and $4 \mathrm{~h}$ ). Ebselen treatment alone did not inhibit spontaneous ROS generation with increased treatment time (Fig. 3A). In order to determine whether ebselen affected TLR or GPX signaling, the effect of LPS and ebselen on AGS cells was investigated (Fig. 3B). H. pylori LPS treatment visibly increased TLR4 protein expression levels with time in AGS cells; however, treatment with ebselen+LPS had no significant effect on TLR4 expression compared with LPS alone (Fig. 3B). H. pylori LPS treatment alone reduced GPX2 and GPX4 expression, however co-treatment with ebselen treatment prevented this effect (Fig. 3B).

Ebselen blocks H. pylori LPS-induced phosphorylation of p38 MAPK. The effect of ebselen on p-p38 MAPK expression levels induced by $H$. pylori LPS treatment was also investigated. Western blotting confirmed that phosphorylation of p38 MAPK was significantly greater in AGS cells treated with LPS compared with cells treated with LPS+ebselen $(\mathrm{P}<0.01$; Fig. 4). These findings suggested that ebselen inhibited the phosphorylation of p38 MAPK induced by $H$. pylori LPS treatment and may be capable of reducing IL-8 expression levels by inhibiting the phosphorylation of p38 MAPK.

\section{Discussion}

Several toxic substances associated with $H$. pylori, including LPS, perform a key role in gastroduodenal diseases. Cytokine induction is triggered by a ROS signal, but the identity of the specific TLR responsible for the recognition of $H$. pylori LPS remains to be determined. Previous studies have implicated TLR4 (10-13), whereas others have suggested a role for TLR2, therefore the exact mechanism is not fully understood. Previous studies have reported the anti-inflammatory activity of ebselen, particularly in human cancer cells $(14,15)$. Ebselen affects extracellular signal-regulated kinase (ERK), c-Jun $\mathrm{N}$-terminal kinase (JNK) and p38 MAPK signaling which are involved in various cellular processes, such as proliferation, differentiation and apoptosis (16-19). The impact of ebselen on these pathways is currently under investigation.

The present study determined that $H$. pylori LPS was important for ROS and IL-8 production in GC cells. LPS significantly increased ROS and IL-8 production, suggesting that it is a major virulence factor for $H$. pylori-associated mucosal inflammation. This effect was inhibited by the anti-inflammatory drug ebselen. Additionally, the present study determined that ebselen had a dose-dependent effect on GC cell viability. In AGS cells, TLR4 expression was increased, but GPX2 and GPX4 expression was decreased by $H$. pylori LPS. In further analysis, ebselen was demonstrated to inhibit the $H$. pylori LPS-induced downregulation of GPX2/4 expression. However, ebselen treatment did not affect TLR4 expression, suggesting that ebselen may inhibit $H$. pylori LPS-induced ROS production via GPX2/4 expression as opposed to TLR4 signaling. This may be due to the fact that ebselen acts as an oxidant at redox-modulatory sites, which mimics the activity of endogenous GPX, therefore partially restores GPX antioxidant capacity $(20,21)$. Furthermore, the present study demonstrated that phosphorylation of p38 MAPK was significantly increased following $H$. pylori LPS treatment and that LPS-induced phosphorylation of p38 MAPK was inhibited by treatment with 


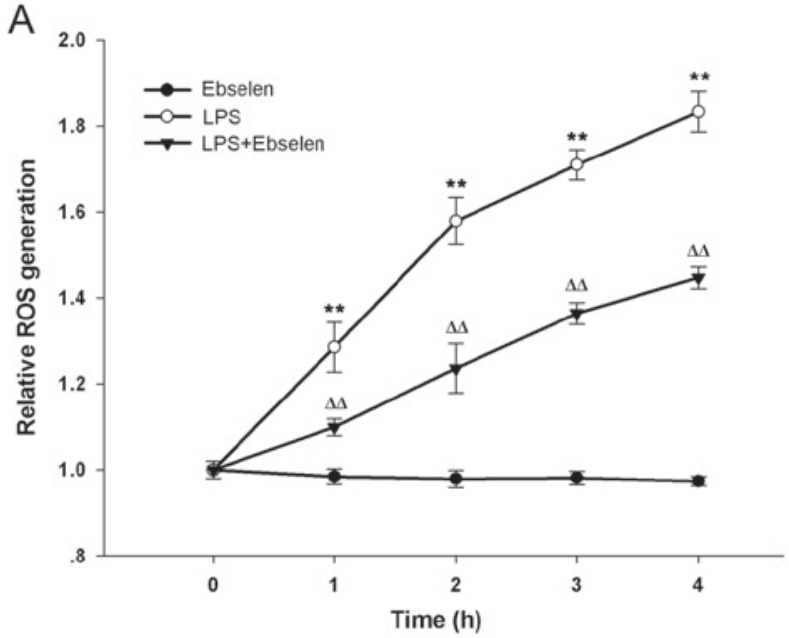

B

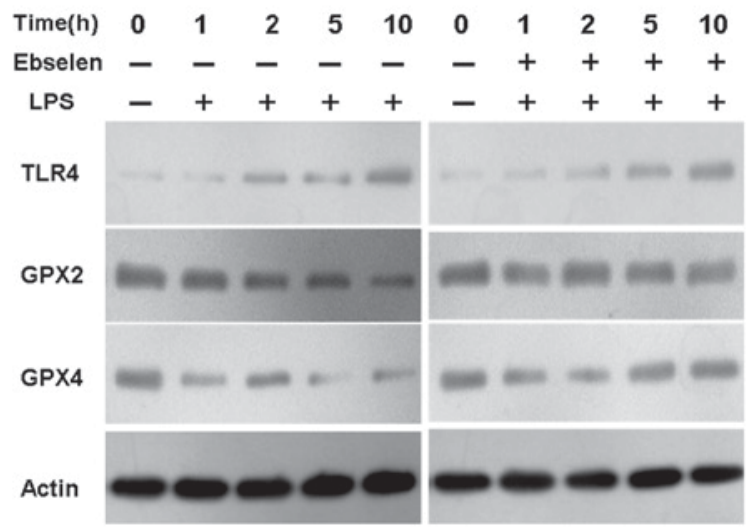

Figure 3. Ebselen inhibits ROS enhanced by Helicobacter pylori LPS via GPX2/4 instead of TLR4 signaling in AGS cells. (A) ROS production. (B) Protein expression levels of TLR4, GPX2, GPX4 and $\beta$-actin were detected by western blotting. ROS, reactive oxygen species; LPS, lipopolysaccharide; TLR4, toll-like receptor 4; GPX, glutathione peroxidase. ${ }^{* *} \mathrm{P}<0.01$ LPS vs. ebselen; ${ }^{\Delta \Delta} \mathrm{P}<0.01$ LPS vs. LPS+ebselen.
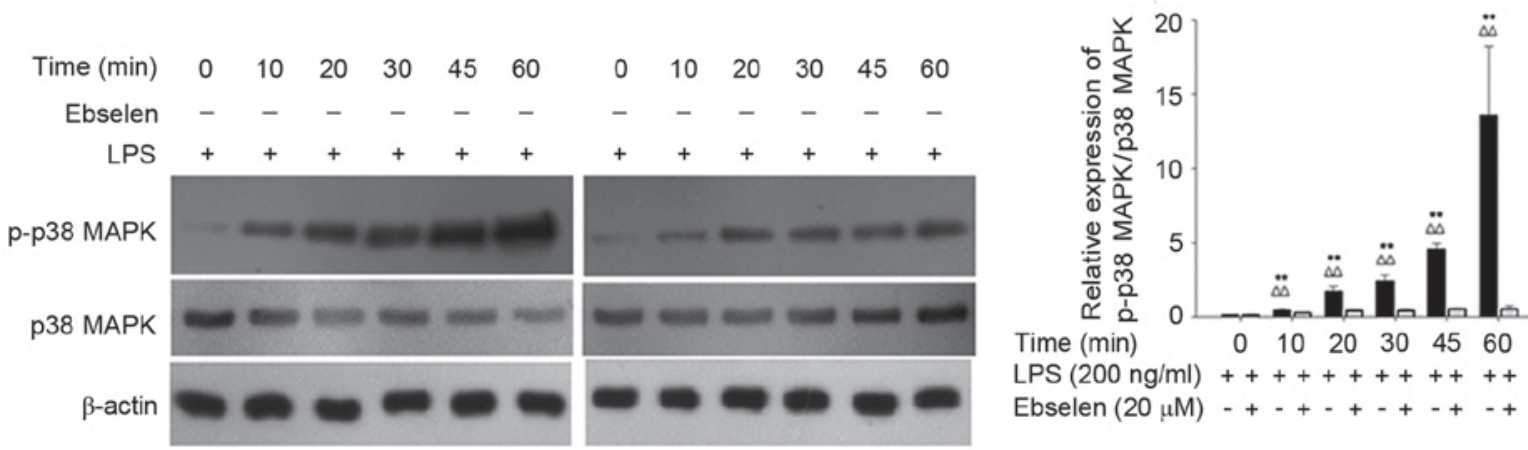

Figure 4. Helicobacter pylori LPS-induced phosphorylation of p38 MAPK in AGS cells is prevented by ebselen treatment. Protein expression levels of p-p38 MAPK, p38 MAPK and $\beta$-actin were detected by western blotting. ${ }^{* *} \mathrm{P}<0.01$ vs. LPS treatment alone at $0 \mathrm{~h} .{ }^{\Delta \Delta} \mathrm{P}<0.01$ vs. ebselen treatment alone at $0 \mathrm{~h}$. LPS, lipopolysaccharide; p-, phosphorylated; p38 MAPK, p38 mitogen-activated protein kinase.

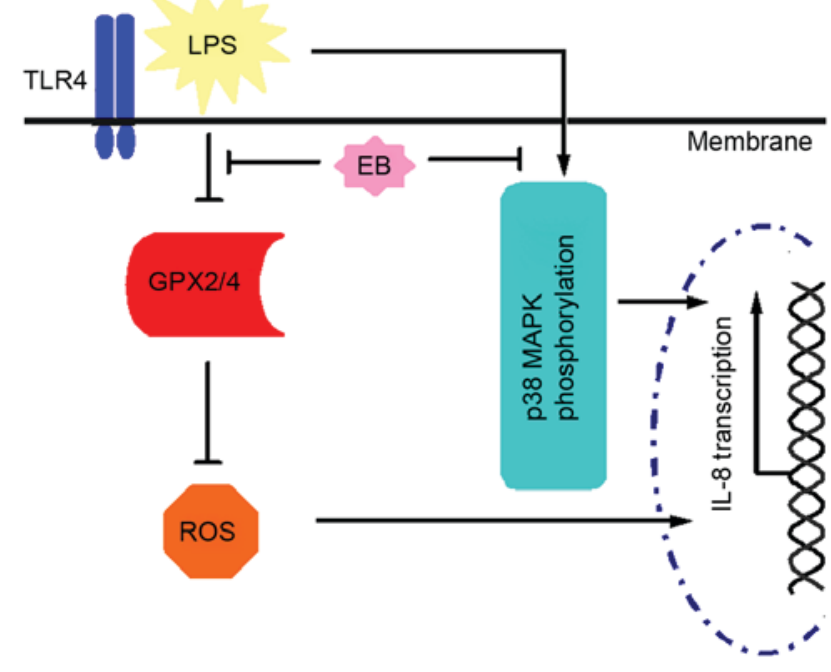

Figure 5. Schematic of proposed signaling pathway based on the results of the present study. Helicobacter pylori LPS inhibits GPX2/4 activation of ROS, which mediates IL-8 expression in gastric cancer cells. EB reverses the effects of $H$. pylori LPS. Additionally, EB blocks the generation of IL-8 by inhibition of p38 MAPK phosphorylation. TLR4, toll-like receptor 4; LPS, lipopolysaccharide; GPX; glutathione peroxidase; ROS, reactive oxygen species; IL-8, interleukin-8; EB, ebselen; p38 MAPK, p38 mitogen-activated protein kinase. ebselen. Therefore, the present study hypothesizes that ebselen disrupted the $H$. pylori LPS-activated ROS/IL-8 pathway by restoring GPX2/4 expression and blocking the generation of IL-8 by inhibiting phosphorylation of $\mathrm{p} 38$ MAPK, as presented in Fig. 5.

The present study revealed that the anti-inflammatory activity of ebselen may be associated with its antioxidative properties. Therefore, ebselen may be a potential therapeutic agent to mediate $H$. pylori LPS-induced cell damage.

\section{Acknowledgements}

Not applicable.

\section{Funding}

The present study was supported by grants from the National Natural Science Foundation of China (grant nos. 81472242 and 81570549), Shanghai Municipal Health Bureau Key Disciplines Grant (grant no. ZK2015A24), Natural Science Foundation of the Science and Technology Commission of Shanghai Municipality, (grant nos. 14ZR1431600 and 14411973700) and the Shanghai Municipal Health Bureau (grant no. 20134100). 


\section{Availability of data and materials}

All data generated or analyzed during this study are included in this published article.

\section{Authors' contributions}

MS and YW conceived and designed the experiments, LX and CG performed the experiments, GL and JW analyzed the data, TW and WM contributed the reagents and materials, and LX wrote the manuscript. All authors read and approved the final manuscript.

\section{Ethics approval and consent to participate}

Not applicable.

\section{Consent for publication}

Not applicable.

\section{Competing interests}

The authors declare that they have no competing interests.

\section{References}

1. Peek RM Jr and Blaser MJ: Helicobacter pylori and gastrointestinal tract adenocarcinomas. Nat Rev Cancer 2: 28-37, 2002.

2. Schistosomes, liver flukes and Helicobacter pylori. IARC working group on the evaluation of carcinogenic risks to humans; Lyon, 7-14 June 1994. IARC Monogr Eval Carcinog Risks Hum 61: 1-241, 1994.

3. Hynes SO, Ferris JA, Szponar B, Wadström T, Fox JG, O'Rourke J, Larsson L, Yaquian E, Ljungh A, Clyne M, et al: Comparative chemical and biological characterization of the lipopolysaccharides of gastric and enterohepatic Helicobacter. Helicobacter 9: 313-323, 2004

4. Esmaeilli D, Mobarez AM, Salmanian AH and Hosseini AZ: Bioactivity and immunological evaluation of LPS from different serotypes of Helicobacter pylori. Iran J Microbio 5: 142-146, 2013.

5. Ogawa T, Asai Y, Sakai Y, Oikawa M, Fukase K, Suda Y, Kusumoto $\mathrm{S}$ and Tamura T: Endotoxic and immunobiological activities of a chemically synthesized lipid A of Helicobacter pylori strain 206-1. FEMS Immunol Med Microbiol 36: 1-7, 2003.

6. Lepper PM, Triantafilou M, Schumann C, Schneider EM and Triantafilou K: Lipopolysaccharides from Helicobacter pylori can act as antagonists for Toll-like receptor 4. Cell Microbiol 7: 519-528, 2005

7. Marthandan S, Hyland P, Pawelec G and Barnett Y: An investigation of the effects of the antioxidants, ebselen or N-acetyl cysteine on human peripheral blood mononuclear cells and $\mathrm{T}$ cells. Immun Ageing 10: 7, 2013.
8. Haddad el-B, McCluskie K, Birrell MA, Dabrowski D, Pecoraro M, Underwood S, Chen B, De Sanctis GT, Webber SE, Foster ML and Belvisi MG: Differential effects of ebselen on neutrophil recruitment, chemokine and inflammatory mediator expression in a rat model of lipopolysaccharide-induced pulmonary inflammation. J Immunol 169: 974-982, 2002.

9. Bernardová K, Babica P, Marsálek B and Bláha L: Isolation and endotoxin activities of lipopolysaccharides from cyanobacterial cultures and complex water blooms and comparison with the effects of heterotrophic bacteria and green alga. J Appl Toxicol 28: 72-77, 2008

10. Uno K, Kato K, Atsumi T, Suzuki T, Yoshitake J, Morita H, Ohara S, Kotake Y, Shimosegawa T and Yoshimura T: Toll-like receptor (TLR)2 induced through TLR4 signaling initiated by Helicobacter pylori cooperatively amplifies iNOS induction in gastric epithelial cells. Am J Physiol Gastrointest Liver Physiol 293: G1004-G1012, 2007.

11. Chochi K, Ichikura T, Kinoshita M, Majima T, Shinomiya N, Tsujimoto H, Kawabata T, Sugasawa H, Ono S, Seki S and Mochizuki H: Helicobacter pylori augments growth of gastric cancers via the lipopolysaccharide-toll-like receptor 4 patyway whereas its lipopolysaccharide attenuates antitumor activities of human mononuclear cells. Clin Cancer Res 14: 2909-2917, 2008.

12. Kawahara T, Teshima S, Oka A, Sugiyama T, Kishi K and Rokutan K: Type I Helicobacter pylori lipopolysaccharice stimulates toll-like receptor 4 and activates mitogen oxidase 1 in gastric pit cell. Infect Immun 69: 4382-4389, 2001.

13. Smith SM, Moran AP, Duggan SP, Ahmed SE, Mohamed AS, Windle HJ, O'Neill LA and Kelleher DP: Tribbles 3: A novel regulator of TLR2-mediated signaling in response to Helicobacter pylori lipopolysaccharide. J Immunol 186: 2462-2471, 2011.

14. Azad GK, Singh V, Mandal P, Singh P, Golla U, Baranwal S, Chauhan S and Tomar RS: Ebselen induces reactive oxygen species (ROS)-mediated cytotoxicity in Saccharomyces cerevisiae with inhibition of glutamate dehydrogenase being a target. FEBS Open Bio 4: 77-89, 2014.

15. Parnham MJ and Sies H: The early research and development of ebselen. Biochem Pharmacol 86: 1248-1253, 2013.

16. Yoshizumi M, Fujita Y, Izawa Y, Suzaki Y, Kyaw M, Ali N, Tsuchiya K, Kagami S, Yano S, Sone S and Tamaki T: Ebselen inhibits tumor necrosis factor-alpha-induced c-Jun N-terminal kinase activation and adhesion molecule expression in endothelial cells. Exp Cell Res 292: 1-10, 2004.

17. Yoshizumi M, Kogame T, Suzaki Y, Fujita Y, Kyaw M, Kirima K, Ishizawa K, Tsuchiya K, Kagami S and Tamaki T: Ebselen attenuates oxidative stress-induced apoptosis via the inhibition of the c-Jun N-terminal kinase and activator protein-1 signalling pathway in PC12 cells. Br J Pharmacol 136: 1023-1032, 2002.

18. Sharma V,TewariR, Sk UH,Joseph Cand SenE: Ebselen sensitizes glioblastoma cells to tumor necrosis Factor (TNFalpha)-induced apoptosis through two distinct pathways involving NF-kappaB downregulation and Fas-mediated formation of death inducing signaling complex. Int J Cancer 123: 2204-2212, 2008.

19. Yang CF, Shen HM and Ong CN: Ebselen induces apoptosis in HepG-2 cells through rapid depletion of intracellular thiols. Arch Biochem Biophys 374: 142-152, 2000.

20. Luo Z, Liang L, Sheng J, Pang Y, Li J, Huang L and Li X: Synthesis and biological evaluation of a new series of ebselen derivatives as glutathione peroxidase (GPX) mimics and cholinesterase inhibitors against Alzheimer's disease. Bioorg Med Chem 22: 1355-1361, 2014.

21. Wang X, Yun JW and Lei XG: Glutathione peroxidase mimic ebselen improves glucose-stimulated insulin secretion in murine islets. Antioxid Redox Signal 20: 191-203, 2014. 